\title{
$\beta$-Blockers and Plasma Renin Activity in Hypertension
}

\author{
G. S. STOKES, M. A. WEBER, I. R. THORNELL
}

British Medical fournal, 1974, 1, 60-62

\begin{abstract}
Summary
Long-term treatment with propranolol was shown to produce a sustained suppression of the renin-aldosterone system in hypertensive patients, despite concurrent diuretic treatment. However, the antihypertensive effect of this treatment correlated poorly with its effects on plasma renin activity and urinary aldosterone excretion. When prindolol, another $\beta$-adrenergic blocking drug, was substituted for propranolol, blood pressure control was retained, but there was a prompt rise in plasma renin activity, which was not attributable to changes in electrolyte balance. These observations suggest that the antihypertensive action of propranolol and other $\beta$ blockers does not result from their effects on plasma renin activity.
\end{abstract}

\section{Introduction}

Recent findings that the $\beta$-adrenergic blocking agents, propranolol and alprenolol, decrease plasma renin activity in both normal and hypertensive man (Bühler et al., 1972; Michelakis and McAllister, 1972; Castenfors et al., 1973) have prompted speculation that this might be the mechanism whereby these drugs lower blood pressure (Castenfors et al., 1973; Lancet, 1973). Such a possibility is not supported by the present studies, in which we examined the effects on blood pressure, plasma renin activity, and urinary aldosterone excretion of propranolol, and of another $\beta$-blocker, prindolol, which has been shown to increase plasma renin activity in rabbits (Weber et al., 1972).

\section{Patients and Methods}

Fourteen hypertensive patients (five males and nine females, aged 15-57 years) were studied. Two had mild impairment of renal function (serum creatinine 2.0 and $2.3 \mathrm{mg} / 100 \mathrm{ml}$ ) and in the remainder serum creatinine was normal.

\section{DETAILS OF STUDIES}

Propranolol (cases 1 to 9).-Patients in this group either had never been treated with antihypertensive drugs or had discontinued their treatment at least one week before study. Ten days before study a metabolic diet containing $100 \mathrm{mEq}$ sodium per day was begun. Control measurements of blood pressure, plasma renin activity, and urinary aldosterone excretion were carried out in a metabolic ward, one to seven days after admission, with the patients in sodium balance. In four cases treatment with propranolol was started in the ward, while the patient continued the metabolic diet, and further measurements were made after three to five days. The other five patients started treatment after discharge from the ward. After three to 14

\footnotetext{
Cardio-Renal Unit, Medical Research Department, Kanematsu Memorial Institute, Sydney Hospital, Sydney, Australia

G. S. STOKES, M.D., M.R.A.C.P., Cardio-Renal Physician

M. A. WEBBER, M.B., Research Fellow

L. R. THORNELL, B.SC., Research Assistant
}

months of treatment as outpatients all were prepared with the same diet, and were admitted to the ward for re-study.

Propranolol-Prindolol Crossover (cases 1 to 4,10 to 14).During chronic treatment with propranolol, patients were admitted to the metabolic ward while in sodium balance on a $100 \mathrm{mEq}$ sodium diet. After completion of measurements of plasma renin activity, urinary aldosterone excretion, and blood pressure in the first 24 hours, the treatment was changed from propranolol to prindolol. The measurements were repeated during 48 hours of inpatient treatment with prindolol, and during six-week periods of outpatient treatment with either drug.

\section{DRUG DOSAGE}

The dose of propranolol was $240 \mathrm{mg} /$ day $(60 \mathrm{mg}$ by mouth every six hours), and the dose of prindolol was $15 \mathrm{mg} /$ day ( $5 \mathrm{mg}$ by mouth every eight hours). Eleven patients (cases 1 to 9,13 , 14) also received the diuretic cyclopenthiazide $0.5 \mathrm{mg} /$ day, which was added two to four weeks after first starting treatment with propranolol.

\section{METHODS}

Blood pressure was measured in the recumbent and erect postures by sphygmomanometer. (Values reported are for recumbency only, as the effects of treatment were similar in both postures.) Mean pressure was derived by adding one-third of the pulse pressure to the diastolic pressure. Values given for ward patients are each the average of five readings during a 24-hour period, while those for outpatients are the average of readings at three to six separate visits. Plasma renin activity was measured by radioimmunoassay after a three-hour incubation at $37^{\circ} \mathrm{C}$ (Haber et al., 1969) in samples collected at 8 a.m. after overnight recumbency and at 11 a.m. after ambulation for three hours. Urinary aldosterone excretion was measured by an isotope dilution technique (Coghlan and Scoggins, 1967). Statistical analysis was by regression analysis and by the Wilcoxon test for pair differences.

\section{Results}

The results of treatment for three to 14 months with propranolol, together with cyclopenthiazide, in nine hypertensive subjects are given in table I. Both the control values and those during chronic treatment were obtained while the patients were in a metabolic ward, taking $100 \mathrm{mEq}$ dietary sodium per day. Control values for plasma renin activity were within the range $0-29 \mathrm{ng} / \mathrm{ml} / 3 \mathrm{hr}$ found in a group of 15 normal subjects taking the same diet. Those for urinary aldosterone were also within the normal range (3-18 $\mu \mathrm{g} / 24 \mathrm{hr}$ ), except for cases 1 and 2, which were increased. Chronic treatment resulted in significant decreases in mean blood pressure and plasma renin activity, both recumbent and erect. Urinary aldosterone excretion was also decreased.

In four patients (cases 4 to 7 ) who were studied during the first three to five days of propranolol treatment there was a decrease in plasma renin activity averaging $66 \pm 18 \%$ of control. This short-term effect was associated with sodium retention, as sodium excretion fell from a control mean of $91 \mathrm{mEq} / 24 \mathrm{hr}$ to 76,31 , and $78 \mathrm{mEq} / 24 \mathrm{hr}$ during the first, second, and third 
TABLE I-Chronic Effects of Treatment with Propranolol*

\begin{tabular}{|c|c|c|c|c|c|c|c|c|}
\hline \multirow{3}{*}{ Case No. } & \multirow{2}{*}{\multicolumn{2}{|c|}{$\begin{array}{c}\text { Mean Blood } \\
\text { Pressure } \\
\text { (mm Hg) }\end{array}$}} & \multicolumn{4}{|c|}{ Plasma Renin Activity (ng/ml) } & \multirow{2}{*}{\multicolumn{2}{|c|}{$\begin{array}{c}\text { Urinarý Aldosterone } \\
\text { Excretion } \\
(\mu \mathrm{g} / \mathbf{2 4} \mathbf{~ h r})\end{array}$}} \\
\hline & & & \multicolumn{2}{|c|}{ Recumbent } & \multicolumn{2}{|c|}{ Erect } & & \\
\hline & C. & $\mathbf{T}$. & C. & T. & C. & $\mathbf{T}$ & C. & $\mathrm{T}$. \\
\hline $\begin{array}{l}1 \\
2 \\
3 \\
4 \\
5 \\
6 \\
7 \\
8 \\
9 \\
\end{array}$ & $\begin{array}{l}182 \\
120 \\
126 \\
158 \\
118 \\
108 \\
166 \\
142 \\
117 \\
\end{array}$ & $\begin{array}{r}93 \\
92 \\
95 \\
92 \\
90 \\
99 \\
120 \\
99 \\
93 \\
\end{array}$ & $\begin{array}{r}9.4 \\
5.9 \\
7 \cdot 2 \\
11.4 \\
2.1 \\
11.6 \\
8.8 \\
0.3 \\
1.7 \\
\end{array}$ & $\begin{array}{r}10 \cdot 1 \\
1.1 \\
2 \cdot 0 \\
2.3 \\
1.3 \\
0.1 \\
0.5 \\
0 \cdot 2 \\
1.8 \\
\end{array}$ & $\begin{array}{r}27 \cdot 0 \\
7 \cdot 4 \\
10 \cdot 3 \\
19 \cdot 6 \\
3 \cdot 8 \\
21 \cdot 0 \\
20 \cdot 4 \\
2 \cdot 4 \\
6 \cdot 7 \\
\end{array}$ & $\begin{array}{r}13.8 \\
1.8 \\
5.9 \\
4.8 \\
0.9 \\
2.4 \\
0.3 \\
0.2 \\
5.0 \\
\end{array}$ & $\begin{array}{r}39 \cdot 2 \\
20 \cdot 4 \\
6 \cdot 4 \\
4 \cdot 2 \\
6 \cdot 9 \\
5.9 \\
7 \cdot 1 \\
12.9 \\
9.5 \\
\end{array}$ & $\begin{array}{r}13.2 \\
1.9 \\
5.1 \\
7.6 \\
5.3 \\
1.7 \\
1.0 \\
8.5 \\
6.5 \\
\end{array}$ \\
\hline$\underset{\text { mean }}{\text { Mean } \pm \text { S.E. of }}$ & $137 \pm 9$ & $97 \pm 3$ & $6.5 \pm 1.4$ & $2 \cdot 2 \pm 1 \cdot 0$ & $13.2 \pm 3.0$ & $3.9 \pm 1.4$ & $12.5 \pm 3.7$ & $5 \cdot 6 \pm 1 \cdot 3$ \\
\hline $\mathbf{P}$ & \multicolumn{2}{|c|}{$<0.01$} & \multicolumn{2}{|c|}{$<0.05$} & \multicolumn{2}{|c|}{$<0.01$} & \multicolumn{2}{|c|}{$<0.05$} \\
\hline
\end{tabular}

*240 mg/day for three to 14 months, together with cyclopenthiazide $0.5 \mathrm{mg} /$ day.
C. $=$ Control. T. = During treatment.

TABLE II-Effects of Crossover from Propranolol to Prindolol

\begin{tabular}{|c|c|c|c|c|c|c|c|c|}
\hline \multirow{3}{*}{ Case No. } & \multirow{2}{*}{\multicolumn{2}{|c|}{$\begin{array}{c}\text { Mean Blood } \\
\text { Pressure } \\
\text { (mm Hg) }\end{array}$}} & \multicolumn{4}{|c|}{ Plasma Renin Activity (ng/ml) } & \multirow{2}{*}{\multicolumn{2}{|c|}{$\begin{array}{l}\text { Urinary Aldosterone } \\
\text { Excretion } \\
(\mu \mathrm{g} / 24 \mathrm{hr})\end{array}$}} \\
\hline & & & \multicolumn{2}{|c|}{ Recumbent } & \multicolumn{2}{|c|}{ Erect } & & \\
\hline & $A^{*}$ & $\mathbf{B}^{*}$ & A & $\mathbf{B}$ & $\mathbf{A}$ & $\mathbf{B}$ & A & $\mathbf{B}$ \\
\hline $\begin{array}{r}1 \\
2 \\
3 \\
4 \\
10 \\
11 \\
12\end{array}$ & $\begin{array}{r}93 \\
92 \\
95 \\
92 \\
109 \\
95 \\
105\end{array}$ & $\begin{array}{r}85 \\
95 \\
89 \\
93 \\
92 \\
93 \\
104\end{array}$ & $\begin{array}{c}10.1 \\
1.1 \\
2.0 \\
2.3 \\
0 \\
0.5 \\
4.5\end{array}$ & $\begin{array}{r}36 \cdot 7 \\
2.4 \\
4 \cdot 6 \\
2.6 \\
0 \\
0 \cdot 7 \\
3.5\end{array}$ & $\begin{array}{r}13.8 \\
1.8 \\
5.9 \\
4.8 \\
0.8 \\
2.8 \\
10.6\end{array}$ & $\begin{array}{r}31.8 \\
4.8 \\
20.4 \\
13.8 \\
1.9 \\
3.3 \\
56.4\end{array}$ & $\begin{array}{r}13.2 \\
1.9 \\
5.1 \\
7.6 \\
3.3 \\
0.9 \\
8.4\end{array}$ & $\begin{array}{r}15.1 \\
11.1 \\
9.0 \\
9.3 \\
1.7 \\
1.3 \\
11.2\end{array}$ \\
\hline Mean & $97 \dagger$ & 93 & 2.9 & $7 \cdot 2$ & $5 \cdot 8$ & 18.9 & $5 \cdot 8$ & $8 \cdot 4$ \\
\hline $\mathbf{P}$ & \multicolumn{2}{|c|}{ N.S. } & \multicolumn{2}{|c|}{ N.S. } & \multicolumn{2}{|c|}{$<0.02$} & \multicolumn{2}{|c|}{$<0.05$} \\
\hline
\end{tabular}

* A = Propranolol $240 \mathrm{mg} / 24 \mathrm{hr}$ for three to 14 months. B $=$ Prindolol $15 \mathrm{mg} / 24 \mathrm{hr}$ for 48 hours.
+ Mean Pretreatment value was $143 \mathrm{~mm} \mathrm{Hg} \pm 9$ S.E. of mean.

days of treatment, respectively, despite a constant intake of $100 \mathrm{mEq} /$ day.

The short-term effects of propranolol on mean blood pressure, observed during the period before the diuretic was added, were closely similar in all nine patients to those observed during chronic treatment with the combined regimen. Thus, there was no appreciable improvement in blood pressure control in this group as a result of adding a diuretic.

The data in table I were analyzed to determine the degree of correlation between the hypotensive effect of chronic treatment and the humoral parameters studied. The change in mean blood pressure correlated poorly with the effects on plasma renin activity, both recumbent and erect, and urinary aldosterone excretion, with the logarithms of these effects (c.f. Bühler et al., 1972), and with the initial level of recumbent plasma renin activity $(r=0 \cdot 26-0 \cdot 43, P>0 \cdot 1)$. It correlated slightly better with the initial level of erect plasma renin activity $(r=0.54$, $P>0 \cdot 1)$ and with the initial level of urinary aldosterone excretion ( $\mathrm{r}=0.63,0.05<\mathrm{P}<0 \cdot 1)$, but these relationships did not reach a level of statistical significance.

The results of changing the treatment from propranolol to prindolol are shown in table II. The effect on blood pressure was minimal. However, erect plasma renin activity increased by a mean ( \pm S.E. of mean) of $188 \pm 39 \%$ and there was also a significant increase in urinary aldosterone. These effects did not result from negative sodium balance, for mean urinary sodium excretion ( $t$ S.E. of mean) fell from $117 \pm 7 \mathrm{mEq} / 24 \mathrm{hr}$ to $88 \pm 7$ on the first day of prindolol and $83 \pm 8$ on the second day. There were no significant effects on the serum concentration or urinary excretion of potassium.

In cases 1 to 4 , studied not only during propranolol and prindolol phases but also before either treatment, it was clear (see graph) that short-term treatment with prindolol retained blood pressure control despite its failure to suppress plasma renin activity.

Equivalent antihypertensive efficacy of the two drugs in the doses given was confirmed in eight patients (cases $1,2,4,9,10$, $11,13,14)$ by outpatient observations made each two weeks

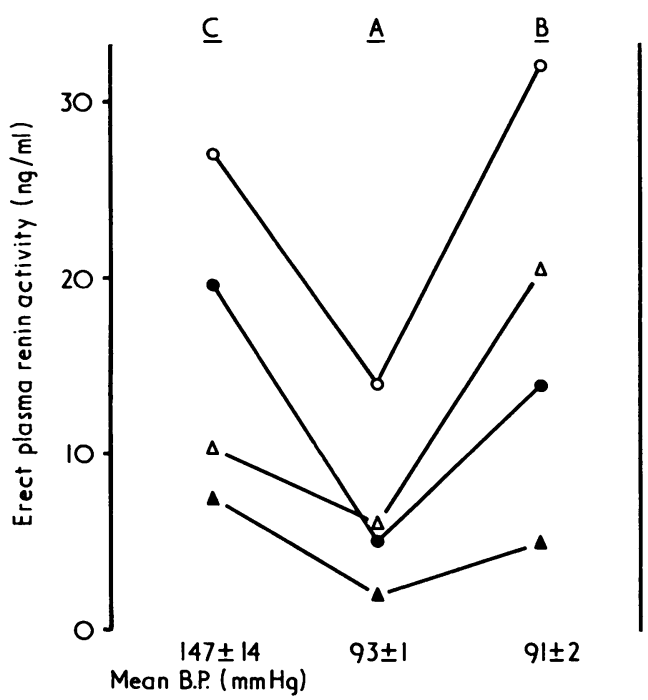

Plasma renin activity in erect posture (dietary sodium intake $100 \mathrm{mEq} /$ day) and mean values ( \pm S.E. of mean) of blood pressure in four hypertensive patients. $\mathrm{C}=$ Control. $\mathrm{A}=$ During chronic treatment with propranolol. $\mathrm{B}=$ After treatment for $\mathbf{4 8}$ hours with prindolol.

during treatment in the sequence: (1) chronic propranolol, (2) prindolol-six weeks, (3) propranolol-six weeks. The withinpatient difference in mean blood pressure was negligible (averaging only $0.5 \pm 2 \mathrm{~mm} \mathrm{Hg}$ ). Mean plasma renin activity ( \pm S.E. of mean) determined from samples collected without control of diet or posture was $5 \cdot 3 \pm 1.7 \mathrm{ng} / \mathrm{ml} 3 \mathrm{hr}$ with propranolol and $14.5 \pm 4.9$ with prindolol $(P<0.2)$

\section{Discussion}

In patients with chronic, propranolol-induced suppression of 
the renin-aldosterone system, the substitution of prindolol for propranolol was shown to increase plasma renin activity. Prindolol was chosen for study because it has a potent antihypertensive effect clinically (Morgan et al., 1972) yet has been shown in rabbits to raise plasma renin activity, an action opposite to that produced by propranolol (Weber et al., 1972). The prindolol:propranolol dose ratio was $1: 16$, intermediate between the ratios of $1: 8$ and $1: 40$ recommended by others for equivalent $\beta$-blocking potency in man (Sandoz, 1968; Hill and Turner, 1969). It proved appropriate in that the antihypertensive effect produced by chronic treatment with prindolol during inpatient and outpatient studies was closely similar to that produced by propranolol. However, the effects of the two drugs on plasma renin activity were different. Prindolol appeared to have little or no inhibitory effect, whereas treatment with propranolol resulted in a prompt and sustained suppression of plasma renin activity, an effect similar to that of alprenolol (Castenfors et al., 1973). This difference may exist because prindolol has a greater intrinsic sympathomimetic activity than the other two agents, being about half that of the reference $\beta$-adrenergic agonist isoprenaline (Barrett and Carter, 1970), a potent stimulator of renin release (Ayers et al., 1969).

Bühler et al. (1972) reported that propranolol reduces plasma renin activity in hypertensive patients and that there is a high degree of correlation between this effect and the antihypertensive action of the drug. However, in common with Michelakis and McAllister (1972), we found little correlation between the hyporeninaemic and hypotensive effects of the drug. This finding, together with the results obtained with prindolol, suggests that the antihypertensive action of propranolol and other $\beta$-adrenergic blocking agents does not depend on suppression of the renin-angiotensin system.

The discrepancy between our data and those of Bühler et al. (1972) is not readily explained. However, in both studies a tendency for sodium retention was noted in some of the patients during the early phase of treatment; subsequently, a moderate dosage of a thiazide diuretic was added in our study, whereas Bühler et al. continued treatment with propranolol only. Thus, it seems reasonable to postulate that the discrepancy arose because changes in plasma renin activity secondary to sodium retention were obviated in our study by the use of a diuretic.

We observed a low degree of correlation, less than that observed by Bühler et al. (1972) in a much larger population of patients, between the fall in blood pressure produced by propranolol and the pretreatment levels of erect plasma renin activity or urinary aldosterone excretion. Though our results do not refute the possibility that, in general hypertensive patients with high plasma renin activity may respond better to treatment with propranolol than those with low plasma renin activity, the suggestion that this reflects a greater involvement of the sympathetic nervous system in the former (Bühler et al., 1972) remains speculative. Indeed, in a recent study of patients with essential hypertension no relation was found between plasma renin activity and urinary catecholamine excretion (Esler and Nestel, 1973).

This work was supported in part by grant in aid G-520 of the National Heart Foundation of Australia, by the Laura Bushall Trust and by the National Health and Medical Research Council of Australia (M.A.W.). The technical help of Mrs. L. M. Stoker and Miss N. aBker is gratefully acknowledged.

Requests for reprints should be addressed to: Dr. G. S. Stokes, Medical Research Department, Sydney Hospital, Macquarie Street, Sydney, 2000, Australia.

ADDENDUM.-Since this paper was submitted our attention has been drawn to the findings of Johnston et al. (1973), which showed that $40 \mathrm{mg} /$ day of prindolol produced a $54 \%$ fall in plasma renin concentration in ambulatory patients. This effect was slightly smaller than that seen with the use of $80 \mathrm{mg} /$ day of propranolol in their study, and much smaller than the fall in plasma renin activity we saw $(70 \%)$ with $240 \mathrm{mg} /$ day of propranolol. Thus, the differences between the two resu'ts may depend upon drug dosage and do not affect our conclusions.

\section{References}

Ayers, C. R., Harris, R. H., and Lefer, L. G. (1969). Circulation Research,

24, Suppl. I, p. 103.

Bürett, A. M., and Carter, J. (1970), British fournal of Phamacology, 40, 373. (1972). New England fournal of Medicine, 287, 1209.

Castenfors, J., Johnsson, H., and Oro, L. (1973). Acta Medica Scandinavica,

193, 189.
Coghlan, J. P., and Scoggins, B. A. (1967). Fournal of Clinical Endocrinology, 27,1470 .

Esler, M. D., and Nestel, P. J. (1973). Australian and New Zealand fournal of Medicine, 3,117.

Haber, E., Koerner, T., Page, L. B., Kliman, B., and Purnode, A. (1969). Fournal of Clinical Endocrinology, 29, 1349.

Hill, R. C., and Turner, P. (1969). British fournal of Pharmacology, 36, 368. Lancet, 1973, 1, 243.

Johnston, C. I., Anavekar, N., Chua, K. G., and Louis, W. J. (1973. Clinical (ecular Medicine, 45, 287

Michelakis, A. M., and McAllister, R. G. (1972). Fournal of Clinical Endocrinology, 34, 386

Morgan, T. O., Louis, W. J., Dawborn, J. K., and Doyle, A. E. (1972). Medical fournal of Australia, 2, 309.

Sandoz Clinical Research Brochure (LB 46) (1968). London, Sandoz products

Weber, M. A., Thornell, I. R., and Stokes, G. S. (1972). Proceedings of the Australian Society of Medical Research, 3, 39. 